\title{
THE RELATIONSHIP BETWEEN SPORT ORGANIZATIONAL MANAGEMENT PRACTICES AND COACHING LEADERSHIP STYLE OF PRIMER LEAGUE FOOTBALL CLUBS IN ETHIOPIAN
}

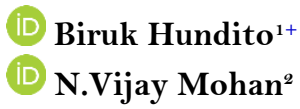

\section{Article History \\ Received: 23 January 2018 Revised: 14 February 2018 Accepted: 19 February 2018 Published: 21 February 2018}

\section{Keywords}

Sport organization, sport management, perceive coaching ,prefer coaching Coaching leadership style football

\author{
${ }^{\prime}$ PhD Research scholar at Andhra University, Visakhapatnam And Lecturer \\ in Dep. of sport studies Wollega university, Ethiopia \\ Email:hunditobiruk@yahoo.com Tel:+919642018387 \\ ${ }^{2}$ Research Director and Head Department of physical education and sport \\ science Andhra University, Visakhapatnam, India \\ Email:vïjaymohansports@gmail.com Tel:+919703831117
}

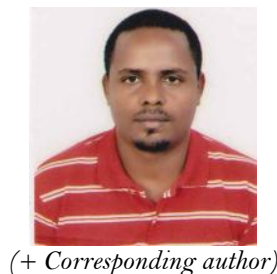

ABSTRACT
The major purpose of this study was to investigate the relationship between sport organizational management practices and coaching leadership style of Ethiopian primer league football clubs. To this end descriptive survey method were employed. The data collected by two Questionnaires the first one from sport organizational management practices and the second one Leadership Scale for Sport (LSS) from selected football club players. Assess the validity and reliability of the questionnaires by areas of professional expertise. The target population of this study were all 14 Ethiopian primer league football club players. Based on Ethiopian football federation rules and regulations 25 players registered for one year computation $25 \times 14(\mathrm{~N}=350)$. The researcher selected only $4(28.57 \%)$ top two and bottom tow clubs from $2015 / 2016$ computation year by using purposive sampling techniques. The total number of participants in this study was $4 \times 25(\mathrm{~N}=100)$. The research approach applied for this study were quantitative approach in nature. The Statistical Package for Social Science (SPSS) version 20 used for data analysis Depending on the nature of the basic questions, appropriate statistical techniques such as mean, standard deviation, ANOVA (analysis of variance) , and Pearson correlation were used for data analysis. The level of significance is set at 0.05 . The researcher assumption/hypothesis was: - There is no significant difference in sport organizational management practices, Perceive and Prefer of coaching leadership behaviour of player's indices in Ethiopian premier league football clubs. The study findings indicated that, there is significant difference between clubs and sport organizational management practice, there is significant difference between clubs and perceive coaching leadership style and there is no significant difference between clubs and prefer coaching leadership style. Finally there was positive relationship in sport organizational management practice, perceive and prefer of coaching leadership behaviour.

Contribution/Originality: This study contributes in the existing literature of develop positive relationship between management, coaching staff and players. The study revealed the existing lapses in sports organizational management practices in the area of human, physical, fiscal and resources management which could promote positive participation and performance in football sports.

\section{INTRODUCTION}

Sport management is a field of education concerning the business aspects of sports and recreation. some examples of sport management includes the front office system in professional managers, recreational sport managers ,sport marketing ,event management ,sport economics, sport finance management , sport personnel 
management ,sport equipment management ,sport policy management, public relation services and sports information.(From Wikipedia, the free encyclopedia) Sport organizational management involves any combination of skills related functions to planning, organizing, directing, controlling, budgeting, leading, and evaluating within the context of an organization or Department whose primary product or service is related to sport or physical activity and Leadership is acritical component to enhance and sustain optimal sport performance (Chelladurai and Reimer, 1998) Gould, Hodge, (Vealey, 2005). A coach is typically responsible for making final decisions on the subject of several team matters, such as strategy, tactics and team personnel (Loughead et al., 2006). A leader is any person who influences individuals and groups within an association, helps them in the setting up of goals, and leading them toward accomplishment of those goals, thereby enables them to be effective. Abioye (1999) stated that sports programmer need to be conducted in such a way that their values and expected results would continue to be appreciated by the participants, organizations, and the general public. Abioye (1999) noted that in order to meet player needs, managers and faculties of training session must continually assess the level of involvement and players reasons for participating in such sports (Obiyemi, 1987). This could only be made possible through good leadership of capable and well informed sports personnel who have knowledge of current sports management. In corroboration with the above statement, Abioye (1999) asserted that an effective and efficient management pattern of sports will afford the participants the opportunity to develop self-realization or individual worth, good human relationship with other players, friends, neighbors, family and fellow citizens. The leaders that immediate supervisors and top-level administrators provide help players understand their roles, performance expectations, and relationship to organizational goals and reward systems. In addition, good leadership enhances employees' personal growth and development, motivation, performance, and team success. Therefore, managers need to have a clear understanding of the dynamics of leadership within organizations (Chelladurai, 1999). Within coaching process, great emphasis is placed on the coach's ability to observe and recall all the critical discrete incidents from a sport performance (Borrie et al., 2002) and Franks and Gary (1986). Chelladurai and Saleh (1978) effective coaching behaviour varies across specific contexts as the characteristics of athletes and the prescribed situation change. The context of the sport situation and characteristics of the coach and the athletes themselves dictate appropriate leadership behaviour. Sports Management and Coaching are intricately linked. Sport Managers often have a background in coaching, or being coached as athletes. Either way sport managers usually have an implicit understanding of what makes a good coach. But do you utilize effective coaching techniques when working with your colleagues and followers? There is a difference between knowing something and doing it. Doing more coaching within your workplace is assured of making a massive difference to your effectiveness as a manager and leader.

However most sport organizations do not emphasize the importance of sport managers to be both leaders and coaches to their followers. Research shows that job candidates value learning and career development opportunities more than most other aspects of a potential job. Your ability to coach your followers through their development could make the difference in recruiting and retaining key employees. If the sports managers and coaches are to achieve their aims and objectives and justify clubs huge investment and enthusiasm for sports development, efficient and effective management practices must be put in place. All management indices to manage sports include policies, personnel, facilities, equipment, public relation, finance, organization structure in sport management which must be made available and effectively managed this directly combined to coaching leadership behaviour like training and instruction, democratic, autocratic, social support, positive feedback Therefore the above ideas indices or parameters are the key focus of the relationship between of the sports management practices, coaching leadership in the selected areas of study in the Ethiopian primer league football clubs. 
Therefore, the results of this study were provide the relationship between sport organizational management practices with better awareness of the effect of their coaching leadership styles on performance and help to determine which coaching leadership styles are most effective for player performance and team success.

\subsection{Objectives of the Study}

To investigate the relationship between sport organizational management practices, with Perceive and Prefer of coaching leadership style of premier league football clubs in Ethiopian.

\section{MATERIALS AND METHODS}

The present study is an applied research in terms of the objectives it pursues. On the other hand, it is a descriptive study of in terms of the nature and the method (correlational method) it employs. The population under study included all 14 Ethiopian primer league football club players. The researcher selected only $4(28.57 \%)$ top two and bottom tow clubs from 2015/2016 computation year by using purposive sampling techniques. The total number of participants in this study $4 \times 25(\mathrm{~N}=100)$. After the data were collected, the raw data were entered into computer and were analysed by SPSS Software (Version 20). Descriptive and inferential statistics were used to analyse the data. Kolmogorov-Smirnov test and shapiro - wilk test was used to test the normality of data distribution and mean, standard deviation, ANOVA (analysis of variance), and correlation were used for data analysis were employed in the study to explore the relationship between variables. To conduct this research, as well as to collect data and information about the variables of the two standardized questionnaires were used as follows: 1.Sport organizational management 2.Self-scale Leadership in Sports. The level of significance is set at 0.05.level .The reliability of the questionnaire in the present investigation: Cronbach's alpha for the questionnaire was a (.823) for sport organizational management, (.852) for perceive coaching leadership behaviour and prefer coaching leadership behaviour $(.834$, , respectively.

\section{RESULTS}

Table-1. Summary of Descriptive Statistics for Means and Standard Deviations sport organizational management practice, Perceived coaching Leadership Style, and Preferred coaching Leadership Style.

\begin{tabular}{|c|c|c|c|}
\hline Sport organizational management practice & $\boldsymbol{N}$ & $\bar{M}$ & $S D$ \\
\hline Financial Managements & 100 & 25.10 & 5.482 \\
\hline Personnel Managements & 100 & 24.50 & 7.053 \\
\hline Facility Managements & 100 & 25.45 & 6.157 \\
\hline Equipment Managements & 100 & 26.22 & 9.927 \\
\hline Organizational structure & 100 & 26.52 & 6.539 \\
\hline Sport policy Managements & 100 & 24.79 & 6.119 \\
\hline Public relation Managements & 100 & 26.63 & 6.108 \\
\hline Perceived Leadership Behaviour & $\boldsymbol{N}$ & $M$ & $S D$ \\
\hline Perceived Training and instruction & 100 & 48.63 & 11.356 \\
\hline Perceived Democratic Behavior & 100 & 31.81 & 8.575 \\
\hline Perceived Autocratic Behavior & 100 & 16.46 & 5.102 \\
\hline Perceived Social Support & 100 & 28.46 & 7.420 \\
\hline Perceived Positive Feedback & 100 & 16.74 & 5.357 \\
\hline Preferred Leadership Behaviour & $\boldsymbol{N}$ & $M$ & $S D$ \\
\hline Preferred Training and instruction & 100 & 50.70 & 10.469 \\
\hline Preferred Democratic Behavior & 100 & 34.95 & 6.929 \\
\hline Preferred Autocratic Behavior & 100 & 18.16 & 4.099 \\
\hline Preferred Social Support & 100 & 30.67 & 6.453 \\
\hline Preferred Positive Feedback & 100 & 18.56 & 4.779 \\
\hline
\end{tabular}

The results of the mean and standard deviations which indicated that Players were sport organizational management practice more with Public relation Managements $(M=26.63$ and $S D=6.108)$ and they sport 
organizational management practice less with Personnel Managements $(M=24.50$ and $S D=7.053)$.than other sport organizational management practice and Players Perceived more Training and instruction $(M=48.63$ and $S D=11.356)$ and also they Players Perceived less Perceived Autocratic Behavior $(M=16.46$ and $S D=5.102)$ than other Leadership Behaviors. And Players Preferred more Training and instruction $(\mathrm{M}=50.70$ and $=\mathrm{SD})$ and Players preferred less Autocratic Behavior $(M=18.16$ and $S D=4.099)$ than other Leadership Behaviors. (See Table 1).

Table-2. Bi-virate Correlation Summary for among sport organizational management practice, perceive and prefer coaching leadership behaviour Variables.

\begin{tabular}{|c|c|c|c|}
\hline Variables & $\begin{array}{l}\text { Sport } \\
\text { Organizational } \\
\text { Management } \\
\text { Practice }\end{array}$ & $\begin{array}{l}\text { Perceive } \\
\text { coaching } \\
\text { Leadership style }\end{array}$ & $\begin{array}{l}\text { Prefer coaching } \\
\text { Leadership style }\end{array}$ \\
\hline Sport organizational Management practice & 1 & & \\
\hline Perceive coaching Leadership style & $.346^{* *}$ & 1 & \\
\hline Prefer coaching Leadership style & $.206^{*}$ & $.560^{* * *}$ & 1 \\
\hline
\end{tabular}

**. Correlation is significant at the 0.01 level (2-tailed)

Source: primary data

When Pearson correlation coefficients were computed among sport organizational management practice , perceive and prefer coaching leadership style variables for players with Ethiopian primer league football clubs , the results indicated moderate positive correlation between sport organizational management practice and perceive coaching leadership style $(r=.346, p \leq .01)$, moderate positive correlation between sport organizational management practice and prefer coaching leadership style $(r=.206, p \leq .01)$ Finally, the bivariate correlation between perceive coaching leadership style and prefer coaching leadership style reveals strongly positive correlation $(r=.560, p \leq .01)$

Table-3. ANOVA Summary for Comparison of sport organizational management practice, perceive and prefer coaching leadership behaviour Variables by clubs

\begin{tabular}{|c|c|c|c|c|c|c|}
\hline \multicolumn{2}{|l|}{ variables } & Sum of Squares & df & Mean Square & $\mathbf{F}$ & Sig. \\
\hline \multirow{3}{*}{ Sport organizational management practice } & Between Groups & 23679.150 & 3 & 7893.050 & 8.570 & .000 \\
\hline & Within Groups & 88415.440 & 96 & 920.994 & & \\
\hline & Total & 112094.590 & 99 & & & \\
\hline \multirow{3}{*}{ Perceive coaching Leadership style } & Between Groups & 17957.800 & 3 & 5985.933 & 7.251 & .000 \\
\hline & Within Groups & 79249.200 & 96 & 825.512 & & \\
\hline & Total & 97207.000 & 99 & & & \\
\hline \multirow{3}{*}{ Prefer coaching Leadership style } & Between Groups & 1746.080 & 3 & 582.027 & .807 & .493 \\
\hline & Within Groups & 69261.760 & 96 & 721.477 & & \\
\hline & Total & 71007.840 & 99 & & & \\
\hline
\end{tabular}

Source: primary data

Table 3 reveals that the mean score for observed sport organizational management practice One way ANOVA shows statistically significant difference between clubs and sport organizational managements at $F=$ $(3,96)=8.570, P=0.000$ is less than 0.05 level of tolerance. Hence the null hypothesis that there is no significant difference between sport organizational management practices of player's indices in Ethiopian premier league football clubs is hereby rejected. And the mean score for observed Percive coaching leadership behavior One way ANOVA shows statistically significant difference between clubs and Percive coaching leadership behavior at $(F=(3,96)=7.251, P=0.000)$ is less than 0.05 level of tolerance. Hence, the null hypothesis that there is no significant difference between in perceive coaching behaviour of players indices in Ethiopian premier league football clubs is hereby rejected.

Finally the mean score for observed Prefer coaching leadership behavior One way ANOVA shows statistically there is no significant difference between clubs and prefer coaching leadership behavior at $(F=$ 
$(3,96)=.807, P=.493)$ is more than 0.05 1evel of tolerance. Hence, the null hypothesis that there is no significant difference between in prefer coaching behaviour of players indices in Ethiopian premier league football clubs is hereby accepted.

Moreover, Tukey post hoc multiple comparison of the mean of the four categories clubs showed that there is signifícant difference between the means of Saint George $\mathrm{Fc}$ and that of Ethiopian Coffee $\mathrm{Fc}$ as reflected by the $(P=$ .000) which is less than 0.05 level of tolerance. And there is signifícant difference between the means of Saint George Fc and that of Ethio- Electric $\mathrm{Fc}_{\mathrm{c}}$ as indicated by the $(P=.014)$ which is less than 0.05 level of tolerance. However, there is signifícant difference between the means of Saint George Fc and that of Hadiya Hossana Fc as indicated by $(P=0.000)$ which is less than 0.05 level of tolerance. there is significant difference between the means of Ethiopian Coffee $\mathrm{Fc}$ and that of Saint George $\mathrm{Fc}$ as indicated by the $(P=.000)$ which is less than 0.05 level of tolerance. And there is no significant difference between the mean of Ethiopian Coffee Fc and Ethio- Electric Fc as indicated by the $(P=.724)$ which is more than 0.05 level of tolerance. However, there is no significant difference between the mean of Ethiopian Coffee $\mathrm{Fc}$ and Hadiya Hossana $\mathrm{Fc}$ as indicated by the $(P=.967)$ which is more than 0.05 level of tolerance. And there is signifícant difference between the means of Ethio- Electric Fc and that of George $\mathrm{Fc}$ as indicated by the $(P=.014)$ which is less than 0.05 level of tolerance. And there is no significant difference between the mean of Ethio- Electric $F_{c}$ and Ethiopian Coffee $F_{c}$ as indicated by the $(P=.724)$ which is more than 0.05 level of tolerance.

The post hoc test revealed there is no statistically significant difference between Ethio- Electric Fc and Hadiya Hossana $\mathrm{Fc}$ as indicated by the $(P=.438)$ which is more than 0.05 level of tolerance. there is signifícant difference between the means of Hadiya Hossana Fc and Saint George Fc as indicated by $(P=0.000)$ which is less than 0.05 level of tolerance. However, there is no significant difference between the mean of Hadiya Hossana $\mathrm{Fc}$ and Ethiopian Coffee $\mathrm{Fc}$ as indicated by the $(P=.967)$ which is more than 0.05 level of tolerance. Finally the post hoc test revealed there is no statistically significant difference between Hadiya Hossana $\mathrm{Fc}_{\mathrm{c}}$ and Ethio- Electric $\mathrm{Fc}$ as indicated by the $(P=.438)$ which is more than 0.05 level of tolerance.

Finally, the multiple comparison of the mean of the four categories club players in Percive coaching leadership style showed that there is signifícant difference between the means of Saint George Fc and that of Ethiopian Coffee $\mathrm{Fc}$ as reflected by the $(P=.014)$ which is less than 0.05 level of tolerance. And there is no signifícant difference between the means of Saint George Fc and that of Ethio- Electric Fc as indicated by the $(P=.986)$ which is more than 0.05 level of tolerance. However, there is no signifícant difference between the means of Saint George Fc and that of Hadiya Hossana Fc as indicated by $(P=.458)$ which is more than 0.05 level of tolerance. there is significant difference between the means of Ethiopian Coffee $\mathrm{Fc}$ and that of Saint George Fc as indicated by the $(P=.014)$ which is less than 0.05 level of tolerance. And there is no significant difference between the mean of Ethiopian Coffee Fc and Ethio- Electric Fc as indicated by the $(P=.035)$ which is more than 0.05 level of tolerance. However, there is significant difference between the mean of Ethiopian Coffee $\mathrm{Fc}$ and Hadiya Hossana $\mathrm{Fc}$ as indicated by the $(P=.000)$ which is less than 0.05 level of tolerance. And there is no signifícant difference between the means of Ethio- Electric $\mathrm{Fc}$ and that of Saint George $\mathrm{Fc}$ as indicated by the $(P=.986)$ which is more than 0.05 level of tolerance. And there is no significant difference between the mean of Ethio- Electric $\mathrm{Fc}$ and Ethiopian Coffee $\mathrm{Fc}$ as indicated by the $(P=.035)$ which is more than 0.05 level of tolerance. The post hoc test revealed there is no statistically significant difference between Ethio- Electric Fc and Hadiya Hossana Fc as indicated by the $(P=.274)$ which is more than 0.05 level of tolerance.

There is no signifícant difference between the means of Hadiya Hossana Fc and Saint George Fc as indicated by $(P=.458)$ which is more than 0.05 level of tolerance. However, there is significant difference between the mean of Hadiya Hossana $\mathrm{Fc}_{\mathrm{c}}$ and Ethiopian Coffee $\mathrm{Fc}$ as indicated by the $(P=.000)$ which is less than 0.05 level of tolerance. Finally the post hoc test revealed there is no statistically significant difference between Hadiya Hossana Fc and Ethio- Electric Fc as indicated by the $(P=.274)$ which is more than 0.05 level of tolerance. 


\section{DISCUSSION}

The objectives of this research was to find out the relationship between sport organizational managements practice and coaching leadership style in premier league football clubs in Ethiopia. Moreover, the research attempted to investigate the relationship between sport organizational management practice variables like finance, personnel ,facilities ,equipment public relation, sport policies and organization structure with coaching leadership styles as perceived and prefer of training and instruction, autocratic behaviour, democratic behaviour ,social support and positive feedback by players premier league football clubs in Ethiopia.

To this end it was found out that Ethiopian premier league football players the mean of under sport organizational management practice variable public relation are better than other and under perceive and prefer coaching leadership style variable training and instruction are better than other. And also there is significant difference between clubs and sport organizational management practice, there is significant difference between clubs and perceive coaching leadership style and there is no significant difference between clubs and prefer coaching leadership style.

The summery of sport organizational management practice are both perceive and prefer coaching leadership style are positive correlation .and Perceive coaching leadership style and prefer coaching leadership style also reveals strongly positive correlation. The finding of the post hoc test results showed that sport organizational management practice, perceive and prefer coaching leadership style were found to be better in the prefer coaching leadership style than other. Management practices are parameters or indices used to enhance the development of sports. Sport organizational managements are positive relationship with coaching leadership style. Abioye (1999) stated that sports programmer need to be conducted in such a way that their values and expected results would continue to be appreciated by the participants, organizations, and the general public. Abioye (1999) noted that in order to meet player needs, managers and faculties of football and training activities must continually assess the level of involvement and players reasons for participating in such football activity program. The effective and efficient management pattern of sports will afford the participants the opportunity to develop self-realization or individual worth, good human relationship with other players, friends, management body, neighbors, family and fellow citizens. Based on the above premise, in Ethiopian football premier league clubs are expected to afford the participants and officials the opportunity to interact with one another and know the type of system of sports management being operated in their various organizations. the managers need to have a clear understanding of the dynamics of leadership within organizations (Chelladurai, 1999). Within coaching process, great emphasis is placed on the coach's ability to observe and recall all the critical discrete incidents from a sport performance (Borrie et al., 2002). The effective coaching behaviour varies across specific contexts as the characteristics of athletes and the prescribed situation change. If sports managers to achieve their aims and objectives and justify clubs huge investment and enthusiasm for sports development, efficient and effective management practices must be put in place. And Complement government efforts in the pursuance of her sports objectives and in the realization of the role to be played in the promotion and development of sports, Much would be gained by identifying, analyzing and relationship between sports management practices, coaching leadership style of premier league football clubs in Ethiopia .

\section{CONCLUSION}

The purpose of this study was to find out the relationship between sport organizational managements practice and coaching leadership style in premier league football clubs in Ethiopia. To this end, the data collected from 100 players from four primer league football clubs who participated 2015/16 Ethiopian primer league football clubs computation. The study employed descriptive and inferential statistics. Data gathered through a questionnaire might have a limitation of indicating appropriately player's in sport organizational management practice and coaching leadership style. In spite of these limitations, the study came up with the 
following major points.

Under the sport organizational management practice are both perceive and prefer coaching leadership style they are positive correlation .and Perceive coaching leadership style and prefer coaching leadership style also reveals strongly positive correlation. The finding of the post hoc test results showed that sport organizational management practice, perceive and prefer coaching leadership style were found to be better in the prefer coaching leadership style than other.

\subsection{Implications}

The purpose of this study was to find out the relationship between sport organizational managements practice and coaching leadership style of premier league football clubs in Ethiopia. In the light of the findings of the study, the following recommendations were forwarded:- the organizational management and coaching staff should promote organizational managements practice, perceive and prefer coaching leadership style among in the team for the better results because if the sport organizational management practices are increases the perception and preference of the player also increases.

Funding: This study received no specific financial support.

Competing Interests: The authors declare that they have no competing interests.

Contributors/Acknowledgement: Both authors contributed equally to the conception and design of the study.

\section{REFERENCES}

Abioye, B.A., 1999. Physical education foundations, practices, principles. Lagos: Macmillan Publishing Company.

Borrie, A., G.K. Jonsson and M.S. Magnusson, 2002. Temporal pattern analysis and its applicability in sport: An explanation and exemplar data. Journal of Sports Sciences, 20(10): 845-852. View at Google Scholar | View at Publisher

Chelladurai, P., 1999. Human resource management in sport and recreation. Champaign, IL: Human Kinetics.

Chelladurai, P. and H.A. Reimer, 1998. Measurement of leadership in sport. In J. L. Duda (Ed.), Advances in exercise and sport psychology measurement. Morgantown, WV: Fitness Information Technology. pp: 227-253.

Chelladurai, P. and S.D. Saleh, 1978. Preferred leadership in sports. Canadian Journal of Applied Sport Sciences, 3: 85-92.

Franks, I.M. and M. Gary, 1986. Eyewitness testimony in sport. Journal of Sport Behavior, 9(1): 38. View at Google Scholar

Loughead, T.M., J. Hardy and M.A. Eys, 2006. The nature of athlete leadership. Journal of Sport Behavior, 29(2): 142-158. Viere at Google Scholar

Obiyemi, O.O., 1987. Management of facility and equipment in the tertiary institutions in Nigeria. Journal of Physical and Health Education, 3: 61-68.

Vealey, R.S., 2005. Coaching fo the inner edge. Morgantown, Wv: Fitness Information Technology. pp: 75-103.

Views and opinions expressed in this article are the views and opinions of the author(s), International Journal of Management and Sustainability shall not be responsible or answerable for any loss, damage or liability etc. caused in relation to/arising out of the use of the content. 